\title{
Gaucher's disease in a patient presenting with hip and abdominal pain
}

\author{
Mustafa Resorlu ${ }^{1 *}$, Nilufer Aylanc ${ }^{1}$, Ozan Karatag ${ }^{1}$, Canan Akgun Toprak ${ }^{1}$ \\ 'Department of Radiology, Faculty of Medicine, Canakkale Onsekiz Mart University, Canakkale, Turkey
}

Study conducted at the Department of Radiology, Canakkale Onsekiz Mart University, Canakkale, Turkey

Article received: $3 / 27 / 2017$ Accepted for publication: 4/3/2017

Correspondence: Canakkale Onsekiz Mart University Terzioglu Yerleskesi, Barbaros Mh Canakkale - Turkey Postal code: 17100 mustafaresorlu77@gmail.com

\section{SUMMARY}

Gaucher's disease is characterized by glucocerebroside accumulation in the cells of the reticuloendothelial system. There are three subtypes. The most common is type 1 , known as the non-neuropathic form. Pancytopenia, hepatosplenomegaly and bone lesions occur as a result of glucocerebroside accumulation in the liver, lung, spleen and bone marrow in these patients. Findings associated with liver, spleen or bone involvement may be seen at radiological analysis. Improvement in extraskeletal system findings is seen with enzyme replacement therapy. Support therapy is added in patients developing infection, anemia or pain. We describe a case of hepatosplenomegaly, splenic infarction, splenic nodules and femur fracture determined at radiological imaging in a patient under monitoring due to Gaucher's disease.

Keywords: Gaucher's disease, tomography, sphingolipidoses.

\section{INTRODUCTION}

Gaucher's disease is an autosomal recessive lipid storage disorder. The beta-glucocerebrosidase enzyme is coded in chromosome 1q21, and the disease results from mutation in this gene. In this lipid storage disease, glucocerebroside is stored in the cells of the reticuloendothelial systems as a result of beta-glucocerebrosidase deficiency. ${ }^{1}$ There are three subtypes of Gaucher's disease, the principal determining characteristic of which is the presence or absence of neurological involvement. Type 1 is the chronic non-neuropathic form, seen in the adult age group. Type 2 is the acute neuropathic form, which is characterized by progressive neurological involvement in addition to hepatosplenomegaly. ${ }^{2}$ Type 3 , the subacute neuropathic form, is seen in children aged between 2 and 6 , and involves mild neurological findings and hepatosplenomegaly. Beta-glucocerebrosidase enzyme deficiency is the common feature of all three subtypes. ${ }^{1,2}$ Glucocerebroside particularly accumulates in the liver, lung, spleen and bone marrow. The clinical manifestations of this accumulation are pancytopenia, hepatosplenomegaly, pulmonary involvement, bone lesions and renal injury. ${ }^{3}$

\section{Case report}

A 56-year-old woman presented to our hospital with hematuria during the previous week and persistent pain in the right hip region during the previous 6 months. She stated that the hip pain began after a minor trauma and persisted despite use of analgesics. Her medical history revealed that she had been diagnosed with Gaucher's disease at the age of 38 and had two siblings with the same condition. She described having anemia since her youth, and reported that bleeding occurred with mild traumas, causing occasional hematuria. Radiography and magnetic resonance imaging (MRI) of the right hip joint revealed edema and fracture in the femoral neck, and decreased convexity, irregularity and osteonecrosis in the femoral head (Figures 1 and 2). Inhomogeneity in bone marrow and focal hypointense areas were also observed in the pelvic bones on T1 weighted series. Abdominal computerized tomography (CT) findings were hepatosplenomegaly, splenic infarction and hypodense nodules in the splenic parenchyma (Figure 3). At laboratory examination, hemoglobin was $9.6 \mathrm{mg} / \mathrm{dL}$ and platelet count, 16,000 . The platelet count failed to increase sufficiently despite transfusion, fracture surgery was postponed at the patient's request, and she was referred to the internal diseases clinic.

\section{Discussion}

Gaucher's disease was first described by Gaucher in 1882 . This lipid storage disease results from mutation in the 


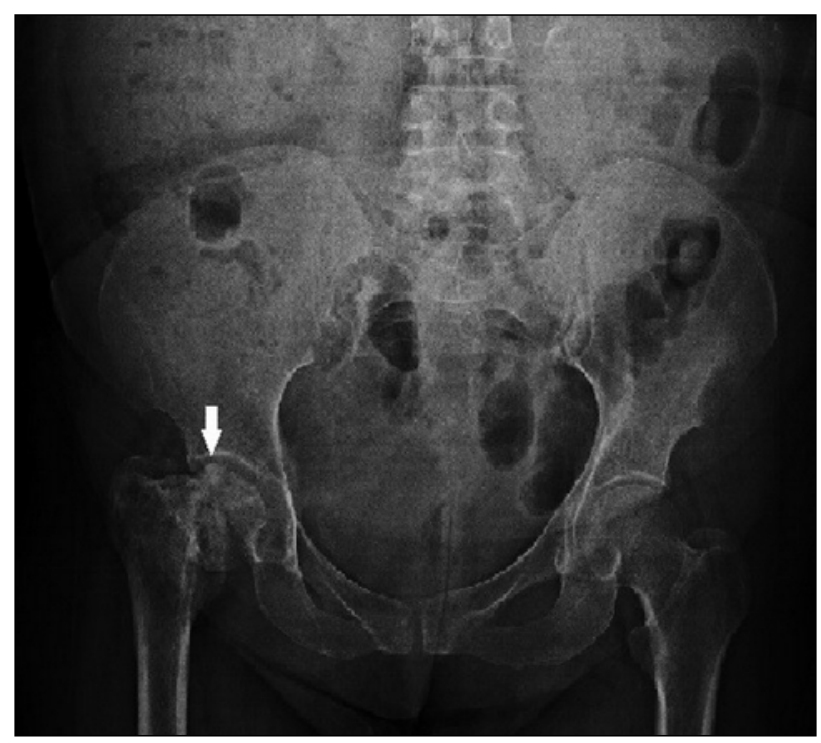

FIGURE 1 Decreased convexity, irregularity and sclerotic foci in the right femoral head.

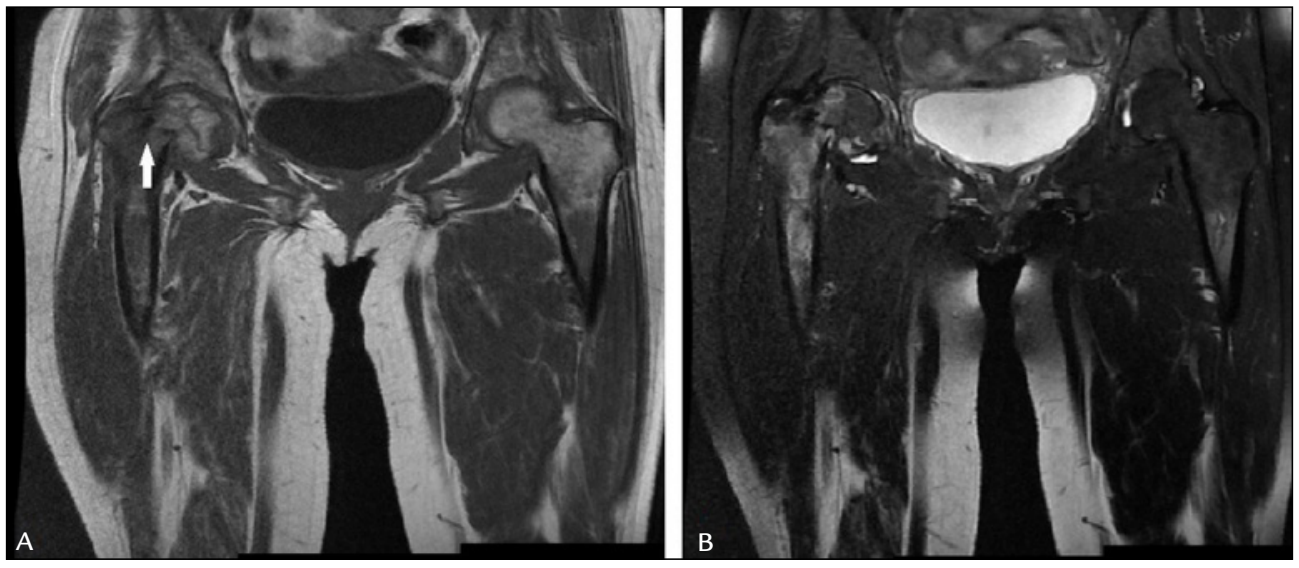

FIGURE 2 Fracture line (A) and bone marrow edema (B) in the femoral neck.

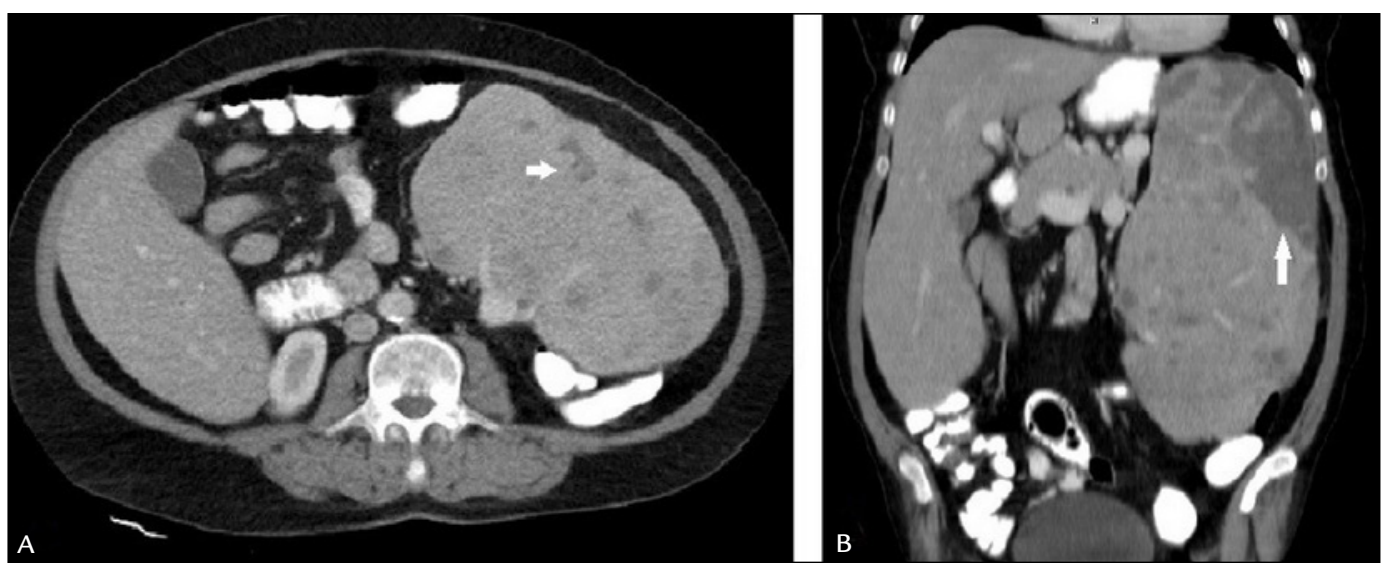

FIGURE 3 Hepatosplenomegaly, splenic nodules (A) and splenic infarct (B) at abdominal CT. 
gene encoding the enzyme beta-glucocerebrosidase. It has been reported to be more common among Ashkenazi Jews. ${ }^{2,4}$ Additionally, multiple myeloma, lymphoma, hepatocellular carcinoma and Parkinson disease are more common in Gaucher patients than in the normal population. ${ }^{3}$ Beta-glucocerebrosidase enzyme activity is impaired as a result of mutations, and glucocerebroside accumulation occurs in the reticuloendothelial system. ${ }^{1,3}$ The most commonly seen subtype is type 1 , characterized by hepatosplenomegaly, hematological findings and bone diseases. ${ }^{2}$ Symptoms commonly occur in the $3^{\text {rd }}$ decade of life in this chronic type. Prognosis is poorer in symptomatic patients in the pediatric age group. ${ }^{2}$

Abdominal pain associated with hepatosplenomegaly is frequently seen among the clinical findings. Infarctions, nodules, portal hypertension and cirrhosis may occur in the liver. Hepatocyte damage, fibrosis around Gaucher cells and collagen bands appear in the liver. Hepatomegaly is present in almost all patients, but impairment of liver functions is rare. ${ }^{4,5}$ In our case, alkaline phosphatase, aspartate aminotransferase and gamma glutamyl transferase enzymes were slightly elevated $(110 \mathrm{U} / \mathrm{L}, 37.4 \mathrm{U} / \mathrm{L}$ and $51 \mathrm{U} / \mathrm{L}$, respectively). Increased biliary excretion of glucosylceramide, hepatic injury and gallstone formation also occur in these patients. ${ }^{1}$ Increasing hemolysis is implicated in the formation of gallstones. However, no gallstone or biliary duct pathology were present in our case.

Splenomegaly is frequently the earliest finding determined. Care must be taken in terms of complications such as bleeding resulting from splenic involvement, increased frequency of infection, hypersplenism, splenic infarct and fibrosis. Rapid growth in the spleen occurs mostly in childhood. If rapid splenic growth occurs in adulthood, hematological malignancy and autoimmune hemolytic anemia must be investigated. ${ }^{6}$

Splenectomy is currently used in the treatment of a limited number of patients. This is due to the possibility of post-splenectomy complications and cell infiltration in bone marrow. ${ }^{7}$ Hypersplenism and bone marrow infiltration play a role in the development of pancytopenia in type 1 Gaucher's disease patients. In our case, the long axis of the spleen was $260 \mathrm{~mm}$, and splenic infarct and intraparenchymal nodular involvement were present. Other hematological findings were anemia persisting for many years, a history of bleeding with minor traumas and hematuria.

The pathophysiology of bone involvement is not fully known, although bone and bone marrow infiltration of Gaucher cells is implicated. The most commonly af- fected bone is the femur, and the most common lesions are osteopenia, osteonecrosis, osteosclerosis and bone infarcts. ${ }^{6}$ Chronic mild joint pain or severe pain mimicking sickle cell anemia may occur. Infarcts cause an acutely painful condition known as bone crisis by increasing intraosseous pressure. Functional imbalances of osteoblasts and osteoclasts impair balance between bone formation and destruction. ${ }^{8}$ The most common radiological findings in bone involvement are Erlenmeyer flask deformity, osteopenia, avascular necrosis and infarction. The radiological appearance of fibrous proliferation and trabecular resorption secondary to infiltration takes the form of cortical thinning, scalloping and radiolucency. Other skeletal findings are compression fracture in the vertebral body, secondary osteoarthritis and pathological fracture. ${ }^{8,9}$

Use of enzyme replacement therapy and support therapy apply in Gaucher's disease. Improvement has been reported in extraskeletal findings and hematological parameters with enzyme replacement therapy. ${ }^{7}$ Support therapy may include antibiotherapy for infections, iron formulations for anemia, analgesic for bone pathologies and surgical procedures. Use of splenectomy is limited and it is generally employed in cases of massive infarct or severe pancytopenia. ${ }^{10}$

\section{Conflict of InTERest}

The authors declare no conflict of interest.

\section{RefEREnCES}

1. Avdaj A, Fanaj N, Osmani M, Bytyqi A, Cake A. Case report of cholelithiasis in a patient with type 1 Gaucher disease. Int J Surg Case Rep. 2016; 29:227-9.

2. Sherwani P, Vire A, Anand R, Gupta R. Lung lysed: a case of Gaucher disease with pulmonary involvement. Lung India. 2016; 33(1):108-10.

3. Langeveld M, Elstein D, Szer J, Hollak CE, Zimran A. Classifying the additional morbidities of Gaucher disease. Blood Cells Mol Dis. 2016; pii:S1079-9796(16)30321-7.

4. Weinreb NJ. Introduction. Advances in Gaucher disease: therapeutic goals and evaluation and monitoring guidelines. Semin Hematol. 2004; 41(4 Suppl 5):1-3

5. Henderson JM, Gilinsky NH, Lee EY, Greenwood MF. Gaucher's disease complicated by bleeding esophageal varices and colonic infiltration by Gaucher cells. Am J Gastroenterol. 1991; 86(3):346-8.

6. Essabar L, Meskini T, Lamalmi N, Ettair S, Erreimi N, Mouane N. Gaucher's disease: report of 11 cases with review of literature. Pan Afr Med J. 2015; 20:18.

7. Weinreb NJ, Barbouth DS, Lee RE. Causes of death in 184 patients with type 1 Gaucher disease from the United States who were never treated with enzyme replacement therapy. Blood Cells Mol Dis. 2016; pii:S10799796(16)30208-X.

8. Wenstrup RJ, Roca-Espiau M, Weinreb NJ, Bembi B. Skeletal aspects of Gaucher disease: a review. Br J Radiol. 2002; 75(Suppl 1):A2-12.

9. Pastores GM, Hermann G, Norton KI, Lorberboym M, Desnick RJ. Regression of skeletal changes in type 1 Gaucher disease with enzyme replacement therapy. Skeletal Radiol. 1996; 25(5):485-8.

10. Fumić K, Stavljenić-Rukavina A, Mrsić M, Potocki K. [Gaucher disease: diagnosis and treatment]. Acta Med Croatica. 2004; 58(5):353-8. 